\title{
What does the feminization of family medicine mean?
}

$\mathrm{F}$ emale family physicians (FPs) now outnumber males, accounting for $50.6 \%^{1}$ of the specialty. This was expected, given the trend within family medicine residency where at least $60 \%$ have been women since 2004. These discrepancies will increase as older, predominantly male, FPs retire. Because family medicine is the largest Canadian medical specialty, this demographic shift has the potential to affect the entire profession. So what does the feminization of family medicine mean to the specialty, profession, patients and society?

Studies show that female FPs practice differently than male FPs. They report working fewer hours per week, (47 v. 52$),{ }^{2}$ seeing fewer patients and taking more interruptions for family reasons. Consequently, workforce projections raise the potential need for more FPs. However, the career pyramid is often inverted for women compared with men. Women experience more family commitment early in their careers. Later, as men consider retirement, women's careers are often taking off and they may practise longer, retiring later. $^{3}$ There is evidence that younger FPs of both sexes now work shorter hours. In Quebec for FPs under 35 years, there is only a two-hour gap between the weekly work hours of women and men (44 v. 46). ${ }^{4}$ Physicians of both sexes want more time for work-life balance. Workforce planning requires adjustment for these societal changes.

Studies ${ }^{3}$ report that female FPs have longer patient visits and engage in more patient-centred communication. Female FPs report greater involvement in preventive care, counselling and psychotherapy than their male counterparts and are more likely to practise intrapartum obstetrics. ${ }^{2}$

Women also outnumber men in pediatrics, geriatrics, endocrinology and medical genetics. ${ }^{1}$ What happens to a discipline when dominated by women? Some would say this represents a success for feminism. Others would suggest that

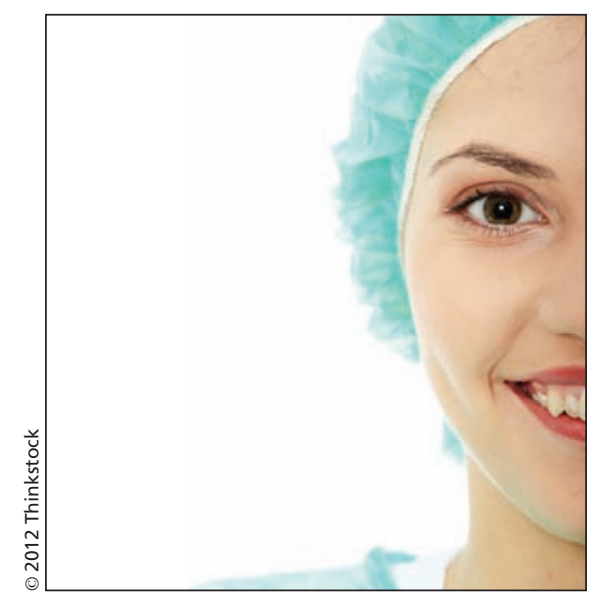

the story is more complex and that higher numbers of women in a discipline lead to a decline in its status. Competing theories explain the possible diminution of prestige associated with a femaledominated profession. One proposes that as a field becomes less attractive to men, they leave - causing a gap that is filled by women. Thus, the loss of prestige predates the influx of women. ${ }^{5}$ Others suggest that the predominance of women lowers the apparent status of a profession. Family medicine has traditionally been undervalued, paid substantially less than other specialties and had difficulty in filling residency positions. It is difficult to isolate the effect of the influx of women on the discipline's status within the profession; however, there is concern that as women cluster in specialties that are considered "softer," a new "pinkcollar" tier of medicine is created. ${ }^{6}$

Is the male FP now an endangered species? Is there a problem when the workforce no longer mirrors the population it serves? Men tend to access health care less frequently than women, raising concerns whether the paucity of male FPs may additionally affect men's health care seeking habits.

Female FPs lag behind their male counterparts in income and are underrepresented in research, academics and leadership. ${ }^{7}$ However, they are achieving academic and political medical leadership positions in unprecedented num- bers. Research supports the existence of a female leadership style that includes being empowering, democratic and transformational. ${ }^{3}$ These qualities are associated with effective leadership and are well suited to multidisciplinary teams or complex organizations. Thus, female FPs are well placed to assume leadership positions, but are often reluctant to do so because of the challenges of adding leadership to clinical and domestic responsibilities. This may become problematic as new family medicine leaders are required to advocate for the discipline.

We raise more questions than answers about the predominance of women within family medicine. Given current trends, this imbalance will increase. We are not suggesting that anything can or should be done to address this imbalance. However, it is important to understand its implications and to study the effects on patient care and the profession. Women may change family medicine itself by their distinct practice and leadership styles. However, their practice patterns, including fewer hours and more leaves, necessitate workforce planning to ensure that patients' needs are met. As these practice patterns become dominant, they may enable all FPs - both men and women - to adopt workloads that foster healthy balance and meaningful involvement with family and community. Finally, female FPs must participate actively in political and academic leadership to ensure that the specialty is not relegated to a "pink-collar" tier of medicine.

\section{Anne Biringer MD \\ Ada and Slaight Family Director of \\ Maternity Care \\ June C. Carroll MD \\ Sydney G. Frankfort Chair of Family \\ Medicine \\ Mount Sinai Hospital \\ University of Toronto \\ Toronto, Ont.}

For references, see Appendix 1, available at www.cmaj.ca/lookup/suppl/doi:10.1503 /cmaj.120771/-/DC1

CMAJ 2012. DOI:10.1503/cmaj.120771

All editorial matter in CMAJ represents the opinions of the authors and not necessarily those of the Canadian Medical Association. 